\title{
Clinical and laboratory assessment of nutritional status
}

\section{By A. Shenkin and Lorna W. Steele, Department of Biochemistry, Royal Infirmary, Glagow $G_{4} \circ S F$}

In recent years, a variety of methods have been developed to provide nutritional support to patients unable to ingest a normal oral diet. These methods include tube feeds, chemically defined or elemental diets and preparations suitable for parenteral infusion. Recognition of the value of these nutritional therapies has led to many studies being performed in order to assess the relative merits of different routes of administration and different types of preparation. Such studies have placed the whole subject of nutritional therapy on a more scientific basis and have necessitated the development of quantitative methods of assessment of nutritional status.

\section{The value of a quantitative assessment of nutritional status}

This type of assessment has been found to be of considerable value in recognizing malnutrition in hospitals. Although it should be possible for all patients to receive an adequate nutritional intake, surveys of hospital patients have indicated that malnutrition is a widespread problem. For example, Bistrian Blackburn, Hallowell \& Heddle (1974) showed that $50 \%$ of the patients in the general surgical wards in their hospital in Boston had evidence of protein-energy malnutrition, and that $35 \%$ of patients had at least one index less than $60 \%$ of normal, suggesting severe nutritional depletion. These general findings were confirmed by Hill, Pickford, Young, Schorah, Blackett, Birkinshaw, Warren \& Morgan, (1977), although their patients were not so severely protein-energy malnourished. However, they observed that the nutritional abnormalities also included anaemia and vitamin deficiency. Not surprisingly, these deficiencies were most frequent in patients more than I week after major surgery.

Protein-energy malnutrition is generally considered to be associated with a number of clinical problems, including poor wound healing (Bozzetti, Terno \& Longoni, 1975), decreased strength of colonic anastamoses (Daly, Vars \& Dudrick, 1972) and with an impaired resistance to infection (Law, Dudrick, \& Abdou, 1974). Having recognized the existence of nutritional depletion, it is therefore necessary to commence nutritional therapy in an attempt to minimize these complications.

When an increased nutritional intake is necessary, it may be difficult to assess the optimal level of supply for the various nutrients in the individual patient. Moreover, even though apparently adequate levels of nutrients are provided, it cannot be assumed that an ill patient will utilize them satisfactorily.

For example, glucose intolerance may occur in the period following injury or sepsis (Stoner \& Heath, 1973). It is therefore necessary to have a quantitative 
method of assessing the progress made by the patient, so that appropriate changes can be made in the dietary regimen. This aspect of nutritional assessment is probably of greater value than the initial recognition of malnutrition since it may permit an objective appraisal of the value of a regimen before obvious clinical changes have occurred.

\section{Clinical assessment of nutritional status}

The clinical assessment must include a good general examination of the patient. This can provide a valuable over-all indication of nutritional state and progress and it should correlate with the various quantified indices of nutritional status. Moreover, it may permit detection of some abnormalities for which there is no easy laboratory test e.g. some vitamin deficiencies.

Changes in body-weight still remain a useful indicator of a change in over-all nutritional status. Although in the short term such changes are unreliable because of changes in fluid balance, over periods of several weeks body-weight changes correlate well with changes in protein-energy nutritional status. Body-weight should be compared with both the individual's usual healthy body-weight as well as with the so-called ideal body-weight for his height, obtained from tables (Jelliffe, 1966).

Measurement of skinfold thickness gives a guide to the amount of adipose tissue stores in the body. Although Durnin \& Womersley (1974) pointed out that the best estimate of subcutaneous fat can be obtained by measuring skinfold thickness at four different sites in the body (biceps, triceps, subscapular and suprailiac), in most hospital patients this is impractical and measurement of the triceps skinfold thickness alone is adequate. One problem is that the correlation of subcutaneous fat with total body fat is both age and sex dependent (Durnin \& Womersley, 1974). Moreover, the range of normality of skinfold thickness is fairly wide. It is therefore very difficult to say whether an individual is depleted or not with respect to his fat stores, on the basis of a single measurement of skinfold thickness and comparison with a normal range. On the other hand, it would seem reasonable to say that if an individual is in good health and has less subcutaneous fat than the so-called ideal value for an individual of the same age and sex, then his ability to withstand a prolonged period of inadequate nutritional intake associated with stress or sepsis may be reduced. Furthermore, in practice the measurement of skinfold thickness can be very valuable since much greater changes can be observed than in measurement of body-weight. Values of less than $50 \%$ of normal skinfold thickness are frequently seen, whereas such a fall in body-weight will usually be fatal unless it has developed very slowly (Keys, Brozek, Henschel, Mickelson \& Taylor, 1950).

A further useful measurement on the upper arm is the mid-arm muscle circumference. This is obtained from the mid-arm circumference by correcting for the amount of subcutaneous fat (Jelliffe, 1966). The muscle circumference of the non-dominant arm provides a good index of the whole-body skeletal muscle, and the values obtained can be compared with standard tables (Jelliffe, 1966). Severe 
depletion of skeletal muscle mass, defined as less than $60 \%$ of normal, is less common than of subcutaneous fat.

\section{Laboratory assessment of nutritional status}

Creatinine height index. An estimate of skeletal muscle mass can also be obtained from urinary excretion of creatinine (Forbes \& Bruining, 1976). In most individuals, creatinine production from creatine is directly related to the skeletal muscle mass, provided there is no very rapid loss of skeletal muscle, as in severe sepsis (Waterlow, Neale Rowe \& Palin, 1972). The ideal or $100 \%$ value for skeletal muscle mass correlates with a given individual's 'ideal' body-weight, and this value in turn correlates with height and can be obtained from tables (Jelliffe, 1966). Population studies have indicated that in males $0.20 \mathrm{mmol}(23 \mathrm{mg})$ creatinine are excreted $/ \mathrm{kg}$ body-weight per $\mathrm{d}$, the comparable level in females being $0.16 \mathrm{mmol}$ (18 mg)/kg per d (Blackburn, Bistrian, Maini, Schlamm \& Smith, 1977). The $24 \mathrm{~h}$ urine creatinine, expressed as a percentage of the calculated ideal value is known as the creatinine height index (Bristrian, Blackburn, Sherman \& Scrimshaw, 1975).

To be of value this assessment requires accurate urine collections. This is best performed over at least two and possibly three consecutive days (Forbes \& Bruining, r976). Furthermore, renal function must be normal. Even with these provisos, we have frequently found a lack of correlation between skeletal muscle mass as estimated by mid-arm muscle circumference and creatinine height index. In general where this occurs, the creatinine height index provides the lower value. In some cases this may be due to measurements having been made on the dominant arm because of intravenous drips etc. Where this is not the explanation, the implication must be that the normal ranges employed are not sufficiently accurate and that it may be necessary to use other age and sex related normal ranges to obtain a better correlation between these estimates of the same body compartment.

There is therefore considerable difficulty in coming to a firm conclusion about nutritional status of fat or skeletal muscle stores, based on one measurement, since the normal ranges are very wide. The measurements only give a guide, and they can be interpreted with greater accuracy if they are all normal or all abnormal. We much prefer to use these measurements in assessing the progress of the illness or the efficacy of treatment (Fig. I).

Plasma proteins. Skeletal muscle comprises about $75 \%$ of the body cell mass (Moore, Olson, McMurray, Parker, Ball \& Boyden, 1963), the remaining 25\% consisting of the viscera. The visceral compartment is of particular importance in maintaining tissue function, protein synthesis and the immune response (Blackburn et al. 1977) and hence its functional and nutritional status should also be assessed.

The main way of doing this is by measuring serum concentrations of proteins synthesized in the liver. These have very different half-lives, or fractional catabolic rates, and hence by measuring a spectrum of these proteins an over-all picture of short-term and long-term effects may be observed (Olusi, McFarlane, Osumkoya \& 


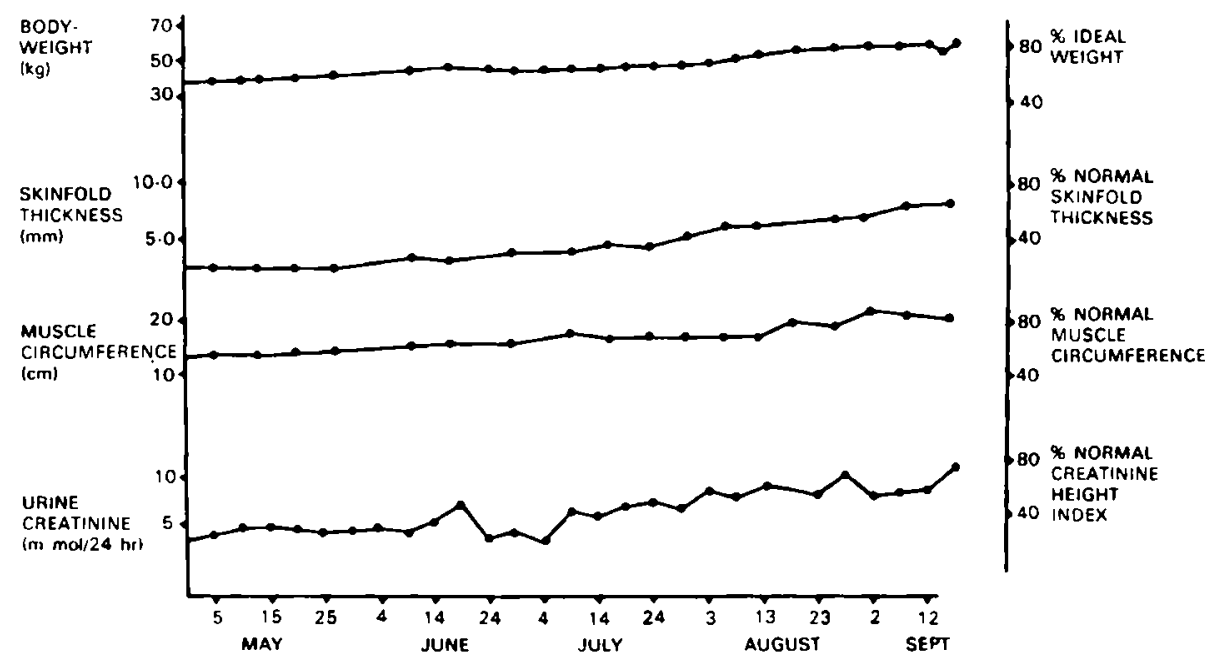

Fig. I. The use of anthropometric measurements and urine creatinine in monitoring the effectiveness of long-term total parenteral nutrition in an 18 year-old boy who had lost $30 \mathrm{~kg}$ bodyweight due to the development of multiple complications following abdominal surgery.

Adesina, 1975; Ingenbleek, Schrieck, Nayer \& Visscher 1975). For example, retinol-binding protein and pre-albumin have very short half-lives of $1-2 \mathrm{~d}$ (Oppenheimer, Surks, Bernstein \& Smith, 1965; Vahlquist, 1972), whereas albumin has a half-life of about $20 \mathrm{~d}$ (Beeken, Valwiler, Goldsworthy, Garby, Reynolds, Stogsdill \& Stemler, r 962). The two most widely used serum proteins for nutritional assessment are albumin and transferrin. However, both are affected by other pathological states. Serum albumin concentration may alter in liver disease or with changes in the albumin space associated with trauma or sepsis. In protein deficiency, serum transferrin concentration falls, whereas in iron deficiency it will rise. When both deficiencies coexist, there may be difficulties in interpretation.

Tests of immune function. A further important assessment of visceral nutritional status includes tests of immune function. A relatively crude test of this is by measuring the total peripheral lymphocyte count. Levels of less than 1200 cells $/ \mathrm{mm}^{3}$ are suggestive of immune deficiency (Blackburn et al. 1977). More sophisticated are the skin tests using subcutaneous injection of antigens such as candida, mumps or streptokinase, streptodornase antigens. These tests are not yet widely used in this country because there have been rare reports of severe reactions especially in obese individuals. If such tests are restricted to persons who are probably malnourished or who are recovering from nutritional depletion, they should be relatively safe. A change from a negative skin test to a positive response is good evidence of improving nutritional status (Blackburn et al. 1977).

Plasma amino acids. A further set of biochemical measurements which may be useful are the plasma amino acid levels. In most normally fed individuals, these levels in the fasting or post-absorptive phase are fairly constant (Scriver, Clow \& Lamm, 1971). In individuals with protein-energy malnutrition, there may be a 
reduction in the total plasma amino acid concentration, this being particularly evident in the branched-chain group of amino acids (Waterlow \& Harper, 1975). Glycine and serine concentrations, on the other hand, may be normal or increased. Two useful ratios of amino acids have been used; the ratios, phenylalanine: tyrosine and glycine: valine, may both be increased in malnutrition. However, short term changes in diet can lead to significant changes in plasma amino-acid concentrations, and hence interpretation of results can be difficult (Waterlow \& Harper 1975).

\section{Assessment of adequacy of protein-energy intake}

All of these measurements can be used both in an initial assessment of a patient and in monitoring the effects of therapy. When a patient has actually been put on a nutritional regimen, two other assessments become relevant: assessing the adequacy of the energy and of the $\mathrm{N}$ content of the regimen.

In assessing the energy requirement of the patient, an estimate of basal energy expenditure (BEE) must first be made. In the absence of direct or indirect calorimetry, one is obliged to resort to Harris-Benedict standards to assess BEE from weight, height, age and sex (Rutten, Blackburn, Flatt, Hallowell \& Cochran, 1975). As a working rule it has been suggested that an oral regimen for maintenance should provide $\mathrm{I} \cdot 2 \times \mathrm{BEE}$, whereas an oral regimen for anabolism should provide at least $\mathrm{I} \cdot 5 \times \mathrm{BEE}$. It seems as though nutrients delivered by the enteral route are somewhat more efficiently used for anabolism than when parenteral nutrition is given, and an intravenous regimen for anabolism should therefore provide at least $\mathrm{I} \cdot 75 \times \mathrm{BEE}$ (Rutten et al. 1975). In the post-trauma or septic patient, the energy requirements may be considerably increased, and a further allowance of 10-100\% may be required (Kinney 1976).

\section{Assessment of nitrogen adequacy}

An assessment of the adequacy of the $\mathrm{N}$ intake in hospital patients remains a difficult laboratory problem. The main type of assessment still is a well-conducted $\mathrm{N}$ balance. Since by far the main $\mathrm{N}$ loss from the body is in the urine, it is important to estimate urine $\mathrm{N}$ losses accurately. Ideally, this is performed by a measurement of total urine $\mathrm{N}$, but this is not routinely available in hospital biochemistry laboratories. A good approximation of this can be made in most patients, provided they are not receiving protein hydrolysates intravenously, if urine urea, which accounts for about $80 \%$ of total $\mathrm{N}$, is measured. Usually, a further $2 \mathrm{~g} \mathrm{~N}$ should then be added to these losses to take account of faecal, skin, hair and other losses. An estimate of $\mathrm{N}$ losses, which is adequate for the majority of patients, is to calculate urine urea $\mathrm{N}+4 \mathrm{~g} / \mathrm{d}$ (Blackburn et al. 1977). An estimate of $\mathrm{N}$ balance can then be obtained, provided the $\mathrm{N}$ intake is approximately known. This, of course, can be difficult in hospital patients, especially if they are receiving an ordinary ward diet. 
Because of the difficulties in measuring $\mathrm{N}$ balance in patients, there have been a number of attempts to find other indices which might be useful in reflecting $\mathbf{N}$ adequacy.

One such measurement is serum ribonuclease (RNase) which some years ago was shown to correlate inversely with $\mathrm{N}$ balance both in protein-energy malnourished children (Sigulem, Brasel, Velasio, Rosso \& Winick, r973), as well as in some groups of adults (Albanese, Lorenze, Orto, Wein, Zavattaro \& de Carlo, 1972). However, serum RNase is affected by other factors, such as renal or hepatic function, which severely limit the applicability of this assay (Shenkin, Citrin, \& Rowan, 1976).

In one recent study, we examined the effects of a short term fast on a number of serum proteins, including RNase (Kihlberg, Callmer, Lindmark, Olsson, Omstedt \& Shenkin, unpublished results). Over an $8 \mathrm{~d}$ fast period, (average daily intake $966 \mathrm{~kJ}(230 \mathrm{kcal}), 0.25 \mathrm{~g} \mathrm{~N})$, the subjects lost on average $4.3 \mathrm{~kg}$ and by the end of this period the urinary $N$ had fallen from 10 to $3.2 \mathrm{~g} / \mathrm{d}$. Thus $\mathrm{N}$ balance was considerably negative throughout. The changes in serum protein concentration are striking (Table $\mathrm{r}$ ).

This study clearly demonstrates that of the proteins measured serum prealbumin and retinol-binding protein are the most sensitive to changes in dietary input. The serum level of complement $\mathrm{C}_{3}$ and of transferrin showed smaller falls, and serum albumin was virtually constant, reflecting its long half-life. Serum RNase, which would have been expected to rise in relation to the negative $\mathrm{N}$ balance, dropped slightly and was therefore not useful in assessing $\mathrm{N}$ balance.

In another recent study, we have demonstrated that in the first week after injury when the concentration of acute phase reactants in serum is high, none of the serum proteins considered in Table I correlated with changes in $\mathrm{N}$ balance (Shenkin, Chao, Neuhauser \& Furst, unpublished results). Measurement of plasma protein concentrations are therefore probably only of value in assessment of nutritional status when the acute phase reaction has subsided.

One further factor of much recent interest is 3-methylhistidine. 3methylhistidine is a component of actin and myosin and is released on catabolism of these proteins (Haverberg, Omstedt, Munro \& Young 1975). It is, however, not reutilized for protein synthesis and is therefore excreted unchanged (Young, Alexis, Baliga, Munro \& Muecke, 1972). The urinary level of 3 -methylhistidine is therefore an index of skeletal muscle catabolism. Unfortunately, interpretation of 3methylhistidine results in isolation can be very difficult. Urinary 3 -methylhistidine may be increased either if protein catabolism is increased as a consequence of the increased anabolism associated with a good diet (Nishizawa, Shimbo, Hareyama \& Funabiki, 1977; Omstedt, Kihlberg \& Shenkin, unpublished results), or because of the increased catabolism associated with the metabolic response to injury when synthesis is probably reduced (Long, Schiller, Blakemore, Geiger, O'Dell \& Henderson, 1977). Hence 3-methylhistidine excretion may be increased in situations of positive or negative $\mathbf{N}$ balance and it cannot therefore be used as a substitute for $\mathbf{N}$ balance estimations. 


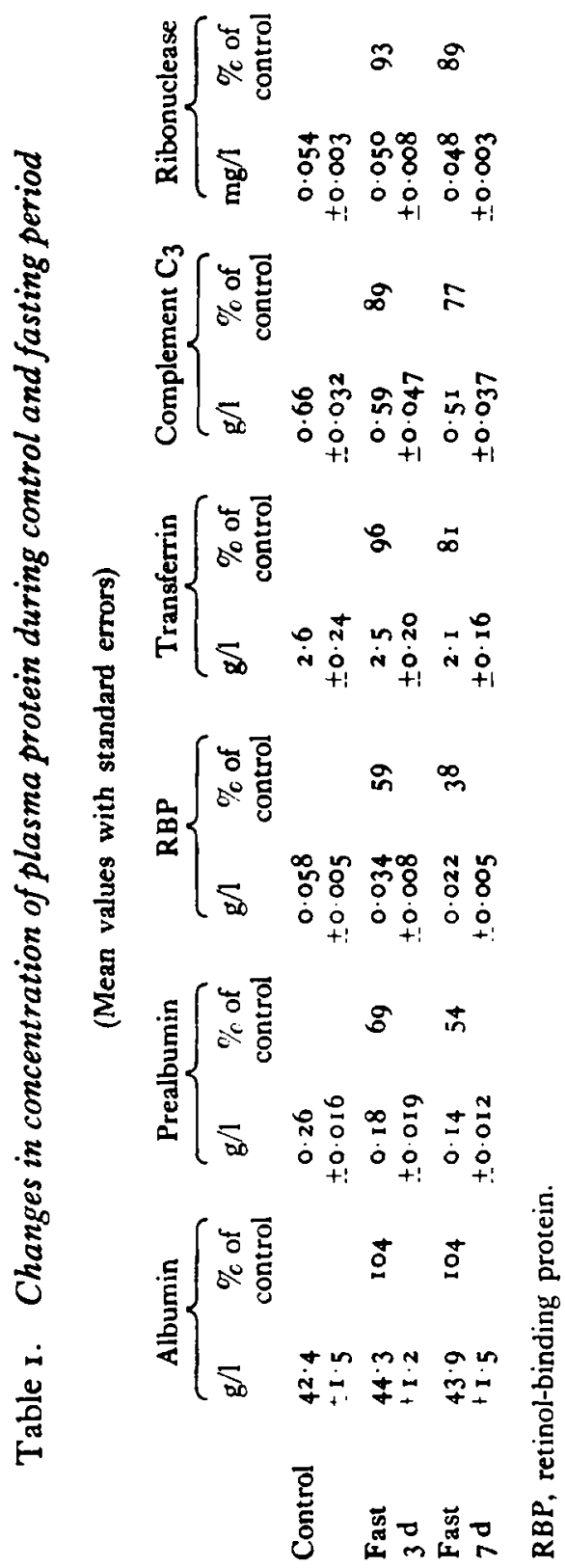




\section{Assessment of vitamin and mineral requirements}

A full nutritional assessment must also include an assessment of vitamin and mineral status. Vitamin status can be assessed partly by clinical examination and partly by measurement of blood levels, either of the vitamins themselves, for example vitamins $A, C$, folate or $B_{12}$, or by assay of enzymes activated by vitamins, for example transketolase for thiamine, or glutathione reductase for riboflavin. Mineral status is best assessed by measurement of both plasma and urine levels of the various important minerals. Those which we routinely estimate are $\mathrm{Na}, \mathrm{K}, \mathrm{Ca}$, $\mathrm{P}, \mathrm{Mg}, \mathrm{Zn}$, and $\mathrm{Cu}$. A fall in plasma level with a concomitant low level of urinary excretion is very suggestive of an inadequate intake.

\section{Protocol for nutritional assessment}

On the basis of the above comments, we would suggest the following protocol for nutritional assessment. An initial measurement of the patient's height is necessary so as to calculate ideal weight and creatinine excretion. Weekly measurement of weight, skinfold thickness, arm-muscle circumference, and a weekly estimate of basal energy expenditure based on weight should all be performed. Laboratory estimations on blood should include on at least a weekly basis measurement of plasma urea and electrolytes, glucose, a selection of plasma proteins including albumin, transferrin and probably prealbumin or retinolbinding protein, liver function tests, and a number of minerals $(\mathrm{Ca}, \mathrm{P}, \mathrm{Mg}, \mathrm{Zn}$,). Vitamin $\mathrm{A}, \mathrm{C}$ and folate should be measured, at least on commencement of any nutritional regimen. Weekly haemoglobin and total lymphocyte count should also be carried out. Urine estimations should be performed on a $2 \mathrm{~d}$ urine collection each week, urine being analysed for creatinine, total $\mathrm{N}$ or urea, and minerals.

This protocol may seem fairly extensive. Nonetheless the majority of the measurements suggested are very simple and can be carried out in any type of hospital and laboratory. The anthropometric measurements are particularly easy to perform. Much of the biochemistry is routine in any clinical laboratory, with the possible exception of some of the specific proteins, some of the minerals e.g. $\mathrm{Zn}$ and $\mathrm{Cu}$, and the vitamins. Working within the limitations of what is available can, however, still provide a fairly comprehensive assessment of nutritional status which should allow rational planning of any nutritional support regimen.

\section{REFERENCES}

Albanese, A. A., Lorenze, E. J., Orto, L. A., Wein, E. H., Zavattaro, D. N. \& de Carlo, R. (1972). N.Y. St. F. Med. I 595.

Beeken, W. L., Valwiler, W., Goldsworthy, P. D., Garby, L. E., Reynolds, W. E., Stogsdill, R. \& Stemler, R. S. (1962). F. clin. Invest. 41, 1312.

Bistrian, B. R., Blackburn, G. L., Hallowell, E. \& Heddle, R. (1974). F. Am. med. Assn. 230, $85^{8}$.

Bistrian, B. R., Blackburn, G. L., Sherman, M. \& Scrimshaw, N. S. (1975). Surgery Gynec. Obstet. 141, 512.

Blackburn, G. L., Bistrian, B. R., Maini, B. S., Schlamm, H. T. \& Smith, M. F. (1977). F. parent. ent. Nutr. I, I 1 .

Bozzetti, F., Terno, G. \& Longoni, C. (1975). Surgery Gynec. Obstet. 141, 712. 
Daly, J. M., Vars, H. M. \& Dudrick, S. J. (1972). Surgery Gynec. Obstet. 134, 15.

Durnin, J. V. G. A. \& Womersley, J. (1974). Br. Y. Nutr. 32, 77.

Forbes, G. B. \& Bruining, G. J. (1976). Am. J. clin. Nutr. 29, 1359.

Haverberg, L. N., Omstedt, P. T., Munro, H. N. \& Young, V. R. (1975). Biochim. biophys. Acta $405,67$.

Hill, G. L., Pickford, I., Young, G. A., Schorah, C. J., Blackett, R. L., Birkinshaw, L., Warren, J. V. \& Morgan, D. B. (1977). Lancet i, 689.

Ingenbleek, Y., Schrieck, H. G., de Nayer, P. \& de Visscher, M. (1975). Clinica chim. Acta $63,6 x$.

Jelliffe, D. B. (1966). Assessment of the Nutritional Status of the Community. Geneva: World Health Organisation.

Keys, A., Brozek, J., Henschel, A., Mickelson, D. \& Taylor H. L. (1950). The Biology of Human Starvation. Vol I. University of Minnesota, North Central Pub. Co.

Kinney, J. M. (1976). In Total Parenteral Nutrition p. 135. [J. E. Fischer, editor]. Boston: Little, Brown and Co.

Law, D. K., Dudrick, S. J. \& Abdou, N. I. (1974). Surgery Gynec. Obstet. 139, 257.

Long, C. K., Schiller, W. R., Blackmore, W. S., Geiger, J. W., O'Dell, M. \& Henderson, K. (1977). Am. F. clin. Nutr. 30, 1349 .

Moore, F. D., Olson, K. H., McMurray, J. E., Parker, H. V., Ball, M. R. \& Boyden, C. M. (1963). In Body Cell Mass and its Supporting Environment. Philadelphia: Saunders.

Nishizawa, N., Shimbo, M., Hareyama, S. \& Funabiki, R. (1977). Br. F. Nutr. 37, 345.

Olusi, S. O., McFarlane, H., Osunkoya, B. O. \& Adesina, H. (1975). Clinica chim. Acta 62, 107.

Oppenheimer, J. H., Surks, M. I., Bernstein, G. \& Smith, J. C. (1965). Science, N. Y. 149, 748.

Rutten, P., Blackbum, G. L., Flatt, J. P., Hallowell, E. \& Cochran, D. (1975). F. Surg. Res. 18, 477.

Scriver, C. R., Clow, C. L. \& Lamm, P. (1971). Am. J. clin. Nutr. $24,876$.

Shenkin, A., Citrin, D. L. \& Rowan, R. M. (1976). Clinica chim. Acta 72, 223.

Sigulem, D. M., Brasel, J. A., Velasio, E. G., Rosso, P. \& Winick, M. (1973). Am. J. clin. Nutr. 26, 793 .

Stoner, H. B. \& Heath, D. F. (1973). Br. $\mathcal{~ . ~ A n a e s t h . ~ 4 5 , ~} 244$.

Vahlquist, A. (1972). Scand. F. clin. Lab. Invest. 30, 349.

Waterlow, J. C., Neale, R. J., Rowe, L. \& Palin, I. (1972). Am. f. clin. Nutr. 25, 37 I.

Waterlow, J. C. \& Harper, A. E. (1975). In Total Parenteral Nutrition-Premises and Promises. p. 23 I. [H. Ghadimi, editor]. London: Wiley.

Young, V. R., Alexis, S. D., Baliga, B. S., Munro, H. N. \& Muecke, W. (1972). 7. biol. Chem. 247, 3592 . 